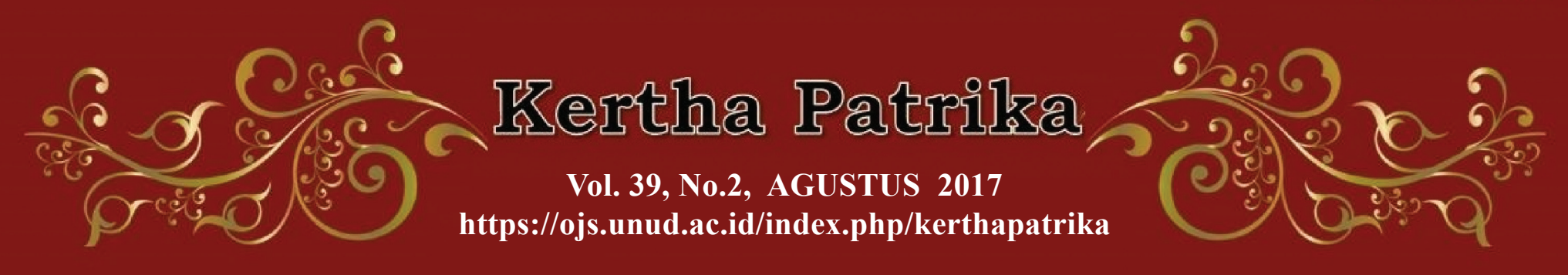

\title{
FORMULASI PENGATURAN DISCLOSURE REQUIREMENTS SUMBER DAYA GENETIK SEBAGAI HAK PATEN
}

Oleh :

Teng Berlianty ${ }^{1}$

Fakultas Hukum Universitas Pattimura Ambon

\begin{abstract}
Abstrak
Lahirnya Undang-Undang Nomor 6 Tahun 1997 tentang Paten (UU Paten) yang diganti dengan UU No Tahun 14 Tahun 2001, kemudian dirubah lagi dengan UU No 13 Tahun 2016 dilandasi oleh kebutuhan bangsa Indonesia untuk memiliki suatu sistem perlindungan hukum bagi penemu dalam bidang teknologi dalam proses industrialisasi. Penelitian ini menggunakan metode yuridis normatif untuk menganalisis peraturan perundangan-undangan yang terkait dengan masalah yang diteliti. Salah satu tujuan UU Paten ini adalah untuk menyempurnakan beberapa ketentuan yang tidak sesuai dengan kebutuhan praktek internasional. Akan tetapi dalam perkembangannya UU Paten tersebut belum sepenuhnya melindungi potensi Sumber Daya Genetik (SDG) (spesies tanaman, hewan maupun mikroorganisme, serta ekosistem) di Indonesia padahal SDG memiliki nilai komersial yaitu dengan mengembangkannya menjadi produk dan proses yang bermanfaat. Beberapa kejadian telah terungkap bahwa negara maju telah menggunakan SDG di Indonesia tanpa aturan yang jelas dan tanpa benefit sharing, sehingga tidak ada alasan bagi Indonesia untuk menolak merumuskan Disclosure Requirements dimasukkan ke dalam UU Paten.
\end{abstract}

Kata Kunci: Formulasi, Disclosure Requirements, Sumber Daya Genetik, Hak Paten.

Abstract

The establishment of Law Number 6 of 1997 on Patent (Patent Law) which was replaced with Law No. 14 of 2001 and then finally changed with Law No. 13 of 2016 is based on the needs of the Indonesia to have a system of legal protection for inventors in the field of technology in industrialization process. This research uses normative juridical method to analyze the legislations related to the problem studied. One of the purposes of this Patent Law is to refine some provisions that are not in accordance with the needs of international practice. However, in its development, the patent law has not fully protect the potential of genetic resources or SDG (species of plants, animals or microorganisms, and ecosystem) in Indonesia whereas SDG has commercial value by developing it into useful products and processes. Several incidents have been revealed that developed countries have used SDG in Indonesia without clear rules and no benefit sharing, so there is no reason for Indonesia to refuse to formulate the Disclosure Requirements which supposed to be incorporated into the Patent Law.

Keywords: Formulate, Disclosure Requirements, Genetic Resources, Patent Right.

DOI: https:doi.org/10.24843/KP.2017.v39.i02.p04

Copyright (C) 2017 Jurnal Kertha Patrika.

\section{Pendahuluan}

Indonesia merupakan salah salah satu negara anggota Organisasi Perdagangan Dunia (World Trade Organization, selanjutnya disingkat WTO). Sebagai bukti eksistensinya menjadi bagian dari masyarakat internasional Indonesia telah mengesahkan keikutsertaannya dan menerima

1 Teng Berlianty adalah Dosen Fakultas Hukum Universitas Pattimura Ambon, korespondensi dengan penulis melalui email : berlianty@yahoo.com. 
KERTHA PATRIKA

Volume 39, Nomor 2, Agustus 2017

Persetujuan Pembentukan WTO beserta seluruh lampirannya melalui Undang-Undang Nomor 7 Tahun 1997 tentang Pengesahan Agreement Establishing The World Trade Organization.

Salah satu persetujuan di bawah WTO adalah Agreement Trade Related Aspect of Intellectual Property Rights (Persetujuan TRIPs). Persetujuan TRIPs) membagi Hak Kekayaan Intelektual (HKI), menjadi 7 jenis yaitu Hak Cipta (Copy Rights), Merek (Trademarks), Indikasi Geografis (Geographical Indication), Desain Produk Industri (Industrial Designs), Paten (Patent), Desain Tata Letak Sirkuit Terpadu (Integrated Circuit Lay-Out Designs), dan Rahasia Dagang (Trade Secret). ${ }^{2}$ Untuk melaksanakan persetujuan TRIPs dan sekaligus membangun sistem hukum nasional di bidang HKI maka dibentuklah berbagai peraturan perundang-undangan nasional di bidang HKI guna meningkatkan kesadaran masyarakat terhadap keberadaan HKI.

Selain ketujuh rezim HKI sebagaimana disebutkan di atas dalam praktiknya masih terdapat rezim HKI yang belum dilindungi secara tegas dalam kerangka persetujuan TRIPs. Rezim HKI ini mengatur masalah hak kekayaan intelektual yang dimiliki oleh komunal atau masyarakat yaitu Genetic Resources, Traditional Knowledge and Folklore (kemudian disingkat menjadi GRTKF). ${ }^{3}$ GRTKF ini merupakan bagian dari identitas negara yang memiliki nilai-nilai moral yang mengandung dimensi budaya, sosial, dan spiritual. GRTKF tidak hanya menjadi identitas semata, tetapi juga menjadi aset potensial yang memiliki manfaat ekonomi dan budaya yang besar. Masalah GRTKF ini telah menarik perhatian masyarakat internasional selama dekade terakhir. Indonesia sebagai negara mega biodiversity dengan keanekaragaman budaya dan adat istiadat sangat berkepentingan terhadap upaya perlindungan terhadap GRTKF. Istilah GRTKF ini dikenal di Indonesia dengan sebutan Sumber Daya Genetik, Pengetahuan tradisional, dan Ekspresi Budaya Tradisional. Yang selanjutnya dalam kajian ini difokuskan pada Sumber Daya Genetik (Selanjutnya disingkat SDG).

Setiap negara memiliki SDG yang menjadi ciri khas negara tersebut. Beberapa negara memiliki banyak SDG di Negaranya. Indonesia merupakan salah satu negara yang memiliki banyak SDG. SDG tersebut dapat mencakup semua spesies tanaman, hewan maupun mikroorganisme, serta ekosistem dimana spesies tersebut menjadi bagian daripadanya.

Indonesia merupakan negara tropis dengan kekayaan SDG yang sangat besar. Oleh karena itu, Indonesia termasuk negara dengan megabiodiversity terbesar kedua setelah Brazil. ${ }^{4}$ Tingginya tingkat keanekaragaman hayati (biodiversity) plasma nutfah ini karena Indonesia memiliki bentang alam yang luas dengan penyebaran dan kondisi wilayah geografis yang bervariasi. ${ }^{5}$

2 Trade Related Aspects of Intellectual Property Rights Including Trade in Counterfeit Goods (TRIPs), Pasal 1 ayat (2).

3 Krisnani Setyowati, 2005, Hak Kekayaan Intelektual dan Tantangan Implementasinya di Perguruan Tinggi, Bogor: Kantor HKI-IPB, h. 179.

4 http://www.antaranews.com/print/369592/masuknya-jenis-ikan-asing-harus-selektif.

5 Roedhy Poerwanto, Iskandar Zulkarnaen Siregar, Ani Suryani, Tanpa Tahun, Merevolusi Revolusi Hijau: Pemikiran Guru Besar IPB (Buku III), IPB Press, h. 528. 
Keberadaan negara berkembang yang memiliki kekayaan alam melimpah seperti SDG menjadi salah satu perhatian penting di tingkat Internasional khususnya dalam hal ini pemanfaatan SDG untuk berbagai kepentingan (bahan pembuat obat, makanan, minuman, pengawet, atau benih) yang berpotensi untuk diambil keuntungannya secara komersial yaitu dengan mengembangkannya menjadi produk dan proses yang bermanfaat, sehingga mendorong perusahaanperusahaan raksasa dari negara maju untuk turut ambil bagian dengan melakukan berbagai tindakan pemanfaatan salah satunya adalah melalui paten. Dampaknya sangat terasa ketika dunia Internasional mulai menggunakan sebagai hak paten sehingga berakibat SDG khas negara-negara berkembang telah dikembangkan dan hak patennya menjadi milik negara lain tanpa izin dan sering kali menimbulkan penjarahan (biopiracy).

Potensi ekonomi dari pemanfaatan dan komersialisasi SDG biasanya melibatkan pengetahuan tradisional dan mendorong terjadinya biopiracy dimana pengambilan keuntungan yang tidak adil dari SDG dan pengetahuan tradisional terkait saat ini dilakukan setidaknya dengan dua cara berikut:

1) Pencurian, penyalahgunaan, atau freeriding sumber daya genetika dan/atau pengetahuan tradisional melalui sistem paten.

2) Pengambilan, pengumpulan tanpa izin untuk tujuan komersial dari sumber daya genetika dan/atau pengetahuan tradisional.

Pemanfaatan SDG oleh Negara maju ini pada akhirnya akan merugikan kepentingan dari Negara berkembang pemilik SDG, oleh karena itu Negara-negara berkembang mendesak untuk membuat suatu aturan baru mengenai permasalahan keanekaragaman hayati dan tuntutan pemberian keuntungan terhadap SDG yang telah dimanfaatkan oleh Negara maju tersebut. Apabila SDG dimanfaatkan dengan semestinya bersama-sama dengan sistem HKI dan dimanfaatkan untuk kepentingan bangsa sendiri hal ini merupakan sinergi yang saling mendukung dalam memperoleh manfaat dari potensi SDG. Dengan melihat kondisi yang ada saat ini, yang umumnya terjadi di negara-negara berkembang termasuk Indonesia, ternyata sistem HKI belum mampu mendorong potensi ekonomi nasional dari pemanfaatan SDG dan justru semakin meningkatkan terjadinya suatu misappropriation atau biopioracy.

Dari realitas tersebut maka upaya Perserikatan Bangsa-Bangsa (PBB) pada Tanggal 5 Juni 1992 di Rio de Janiero diadakan kesepakatan dengan dikeluarkannya Convention on Biological Diversity (CBD), Brazil. CBD melahirkan suatu prinsip Access Benefit Sharing (ABS). Prinsip ini mempunyai keterkaitan dengan instrumen penting Hak Kekayaan Intelektual (HKI) yaitu TRIPs Tahun 1994, dimana SDG termasuk salah satu yang dilindungi oleh sistem HKI. Akan tetapi TRIPs tidak memfasilitasi tentang SDG, dimana pengaturan dalam TRIPs menempatkan Negara pemilik SDG menjadi Negara yang tidak memperoleh manfaat dan keuntungan ketika SDG mereka dipatenkan oleh pihak asing terutama Negara maju. 
Dengan ketentuan-ketentuan yang terdapat dalam TRIPs, terdapat penolakan dari Negaranegara maju untuk memenuhi tuntutan dari Negara berkembang dalam melindungi SDG nya. ${ }^{6}$ Negara maju beranggapan bahwa SDG adalah warisan peradaban manusia (the common heritage of mankind) dan bukanlah milik Negara dimana tempat SDG itu berada, sehingga siapapun berhak untuk mengambil dan memanfaatkannya.

Saat ini di forum internasional tengah berkembang wacana keterbukaan sumber invensi (disclosure requirements), khususnya dalam penerapan sebagai salah satu syarat formal apllikasi paten. Wacana ini berkembang sejalan dengan terungkapnya kasus-kasus paten atas obat-obatan yang terkait dengan SDG dan Pengetahuan Tradisional (PT), dimana paten memberikan hak monopoli kepada pemegang haknya. Wacana itu berkembang di dalam forum resmi seperti pada CBD dan (WTO).

Sistem perlindungan paten tidak terdapat ketentuan mengenai keharusan untuk adanya keterbukaan informasi tentang sumber invensi. Itu sebabnya negara-negara maju yang diuntungkan dengan sistem paten yang berlaku sekarang ini cenderung mempertahankan ketentuan yang ada. Sebaliknya, Negara berkembang dimana SDG nya banyak dimanfaatkan oleh negara maju menginginkan agar aturan hukum paten yang ada mencerminkan rasa keadilan dengan memasukkan prinsip keterbukaan informasi tentang sumber invensi. Adanya keterbukaan informasi sumber ini akan mempunyai pengaruh bagi negara-negara berkembang sebagai landasan yang kuat untuk menuntut adanya pembagian yang adil atas pemanfaatan SDG dan PT oleh negara maju. Selain itu dengan adanya pembagian keuntungan dapat menjaga kelangsungan SDG dengan suatu perlindungan terhadap SDG secara berkelanjutan melalui konservasi sumber daya alam.

Dengan demikian, masalah yang dirumuskan adalah bagaimana formulasi pengaturan disclosure requirements dimasukkan dalam UU Paten untuk mendukung perlindungan SDG di Indonesia.

\section{HASIL DAN PEMBAHASAN}

\subsection{Pemanfaatan Sumber Daya Genetik Dalam Sistem Paten}

SDG sebagai sesuatu yang ada di alam, tidak seharusnya diberi perlindungan paten. Namun keduanya perlu dilindungi dari penjarahan, bagaimana halnya dengan invensi yang berkaitan dengan SDG? apakah invensi semacam itu dapat dimintakan paten?

Paten merupakan salah satu jenis HKI yang berkaitan dengan pemanfaatan SDG. Ketentuan dalam sistem paten yang terkait dengan pemanfaatan SDG adalah:

6 R Anton Suyatno, 2012, Pemanfaatan Penundaan Kewajiban Pembayaran Utang Sebagai Upaya Mencegah Kepailitan, Jakarta: Kencana Prenada Media Group, h. 1.

7 The common heritage of mankind ini semacam konsep res communis dalam Hukum Romawi yang diterapkan pada hukum laut Internasional, dimana konsep ini merujuk ke wilayah bukan milik siapa-siapa (belong to no one) yang bisa dimanfaatkan umum. 
1. Paten diberikan untuk setiap invensi, baik produk maupun proses, dalam semua bidang teknologi sepanjang invensi tersebut baru, mempunyai langkah inventif dan dapat diterapkan dalam industri (TRIPs Pasal 27 Ayat 1 dan UU Paten).

2. Bahwa Mikroorganisme baik yang telah ada di alam atau hasil rekayasa genetika merupakan subyek matter yang patentable (lihat TRIPs Pasal 27(3). Kedua Pasal di atas menjadi penting dalam kaitannya dengan pemanfaatan SDG karena:

a. Perjanjian TRIPS memungkinkan diberikannya paten untuk material genetika (dan produk-produk turunan-nya) dan juga varietas tanaman tertentu (dengan sistem sui generis). Perjanjian TRIPs tidak mengatur bagaimana hak paten atau varietas tanaman diperoleh, apakah konsisten atau tidak dengan hak negara (sovereignty) asal dari sumber daya genetik tersebut, ada ketidak seimbangan antara negara berkembang sebagai pemilik sumber daya genetik dan negara maju dengan kemampuan teknologinya.

b. Perjanjian TRIPS tidak mempunyai pembatasan bagi paten yang dihasilkan dari pengetahuan tradisional yang berarti bertentangan dengan Pasal 8 (j) dari Convention on Biological Diversity (CBD).

c. Perjanjian TRIPS menyediakan per-lindungan material genetika (dan produk-produk turunannya) melalui paten, tanpa memastikan bahwa ketentuan dari CBD, yang meliputi prior informed consent dan benefit sharing dipertimbangkan.

Indonesia merupakan Negara kepulauan yang terdiri atas lebih dari 13.000 pulau, dimana Indonesia terletak dalam lintasan distribusi keanekaragaman hayati benua Asia (Pulau Jawa, Sumatera dan Kalimantan) dan benua Australia (Pulau Papua) serta sebaran wilayah peralihan Wallacea (Pulau Sulawesi, Maluku dan Nusa Tenggara). Walaupun hanya melingkupi 1,3\% dari luas total daratan dunia, Indonesia memiliki keanekaragaman hayati yang sangat tinggi. ${ }^{8}$

Keanekaragaman hayati memberikan nilai konsumsi dalam bentuk pangan, sandang maupun papan. Masyarakat Indonesia mengonsumsi tidak kurang dari 100 spesies tumbuhan biji-bijian dan ubi-ubian sebagai sumber karbohidrat. Tidak kurang dari 100 spesies kacangkacangan, 450 spesies buah-buahan serta 250 spesies sayur-sayuran dan jamur juga digunakan dalam menu makanan masyarakat, sementara 940 spesies tanaman menghasilkan bahan untuk obat tradisional, dimana obat tradisional ini banyak bermanfaat di dalam industri farmasi yang memiliki nilai potensi ekonomi yang tinggi. ${ }^{9}$

Pasal 3 Convention on Biological Diversity (CBD) menegaskan bahwa setiap Negara memiliki kedaulatan untuk mengeksploitasi sumber daya alamnya sesuai dengan kebijakan pembangunan dan lingkungannya, sebagai berikut:

"States have, in accordance with the Charter of the United Nations and the principles of international law, the sovereign right to exploit their own resources pursuant to their

8 Country Profile Indonesia dalam Balai Kliring Keanekaragaman Hayati, http://bk.menlh.go.id/?module=pages\&id= cprofile.

9 Ibid. 
own environmental policies, and the responsibility to ensure that activities within their jurisdiction or control do not cause damage to the environment of other States or of areas beyond the limits of national jurisdiction.

Hak berdaulat Negara atas SDG sebagaimana diakui di dalam Pasal 3 CBD juga dipertegas di dalam ketentuan Pasal 15 CBD. Penerapan pasal ini berimplikasi pada diakuinya otoritas Negara untuk mengontrol akses atas SDG yang dimilikinya melalui legislasi nasional. Selain itu di dalam konstitusi Indonesia, hak berdaulat negara atas sumber daya alamnya juga dapat ditemukan yaitu di dalam Pasal 33 ayat (3) Undang-Undang Dasar Negara Republik Indonesia Tahun 1945 (UUD NRI Tahun 1945). Pasal ini merumuskan prinsip konservasi dalam arti kata: pemanfaatan kekayaan alam untuk sebesar-besarnya kemakmuran bagi sebanyak mungkin penduduk bangsa Indonesia.

Potensi yang melekat pada SDG berupa pemanfaatan dan upaya pengembangan SDG dapat dilakukan baik secara tradisional maupun secara moderen. Pemanfaatan SDG secara tradisional dilakukan yaitu berupa upaya untuk mendapatkan karakter unggul pilihan melalui pemilihan jenis dan persilangan yang dilakukan secara empiris. Sedangkan pemanfaatan SDG secara modern dilakukan setelah era mendel yang mulai menggunakan teknik hibridasi yang merupakan titik awal dari upaya manusia dalam menyeleksi ekspresi genetik dan variabilitas gen di dalam tumbuhan secara sistematis. ${ }^{10}$

Komersialisasi SDG dilakukan sebagai upaya pengembangan dan pemasaran suatu produk dari hasil penerapan proses bioteknologi. pemasaran produk bioteknologi banyak berlangsung diluar negeri, baik produk yang telah mempunyai label maupun produk yang belum mempunyai label. Hasil produk bioteknologi yang paling banyak adalah berasal dari tanaman jagung, kedele, dan kapas, dimana Amerika Serikat merupakan negara yang paling banyak menanam tanaman bioteknologi. ${ }^{11}$

Pemanfataan SDG mempunyai implikasi pada ketahanan pangan lokal dan nasional. Pemberian hak paten atas varietas baru tanaman pangan tanpa dibuka sumber dari SDG serta pengetahuannya akan menjadi proses penjarahan (biopiracy). Dalam hal ini kasus Tukirin dkk di Jawa Timur menjadi tolok ukur yang baik. Tukirin dkk dituduh menjiplak cara pemuliaan jagung yang dilakukan PT BISI. Memang jagung yang dijadikan obyek pemuliaan bukanlah varietas petani, tetapi kasus Basmati di India jelas- jelas adalah kasus varietas petani yang direkayasa kemudian dimintakan paten. Selanjutnya petani India dilarang mengekspor padi Basmati yang dipatenkan perusahaan Eropa tersebut. Dalam kondisi krisis pangan yang sudah di pelupuk mata, liberalsiasi sistem paten atas SDG dan ketiadaan peraturan yang jelas tentang pengendalian akses atas SDG, ditambah ketiadaan perlindungan bagi pengetahuan masyarakat atas SDG, akan memperburuk upaya mengadakan ketahanan pangan dengan sumberdaya di dalam negeri.

\footnotetext{
${ }^{10}$ Krisnani Setyowati, Op.Cit, h.144.

${ }^{11} \mathrm{Ibid}$.
} 
SDG dapat dilingdungi paten, walaupun berbeda dalam memahami pemanfaatn SDG merupakan hak paten. Dari sudut pandang liberalisme paten, invensi apapun, termasuk yang tersambung dengan SDG selalu dapat dimintakan paten, asalkan memenuhi semua persyaratan standar berupa: novelty (kebaruan), non-obvious (bersifat inventif), and useful (kebergunaan). Persyaratan tersebut bersifat universal, seperti misalnya tercantum dalam perjanjian internasional TRIPs (Hak Kekayaan Intelektual terkait Perdagangan), di bawah Organisasi Perdagangan Dunia (WTO). Doktrin utamanya adalah kepatuhan terhadap kesepakatan. Prinsip dasarnya adalah Pact Sunt Servanda (janji harus ditepati). Akan tetapi dalam persyaratan novelty, invensi yang tersambung dengan SDG tidak dapat dipatenkan, karena tidak memenuhi syarat kebaruan (novelty). Acuan utamanya adalah kasus aplikasi atau pemberian paten atas tanaman nimba, kunyit dan beras basmati. Pada kasus-kasus ini paten yang sudah diterbitkan kemudian dibatalkan karena syarat kebaruan tidak terpenuhi.

Atas dasar syarat kebaruan maka perlindunggan SDG dalam sistem paten dapat mengacu pada keterbukaan (disclosure), sehingga invensi yang tersambung dengan SDG tetap dapat dipatenkan, asalkan ketika mengajukan permohonan paten atas invensi tersebut dinyatakan secara transparan bahwa invensi tersebut terkait dengan SDG. Hal ini karena tidak mungkin ada invensi yang benar-benar baru (novel). Pada umumnya invensi yang patentable (bisa diberikan paten) merupakan hasil pengembangan dari invensi-invensi sebelumnya, atau sekurangkurangnya hasil perkembangan dari teknologi yang sudah ada sebelumnya. Termasuk di dalamnya adalah teknologi yang bersumber dari pengetahuan tradisional tentang pemanfaatan sumberdaya genetika tertentu. Banyak riset di bidang farmasi yang melibatkan pengetahuan tradisional sebagai basis awalnya.

\subsection{Manfaat Disclosure Requirements Bagi Indonesia}

Saat ini di forum internasional tengah berkembang wacana keterbukaan sumber invensi (disclosure requirements). Wacana ini berkembang sejalan dengan terungkapnya kasus-kasus paten obat-obatan yang terkait dengan SDG. Wacana itu berkembang di dalam forum resmi seperti pada CBD dan WTO. Tuntutan disclosure requirements muncul ketika industri farmasi dari negara maju memperoleh manfaat dari penggunaan SDG dari negara berkembang tanpa adanya pembagian manfaat yang adil (equitable benefit sharing). Sementara itu di dalam sistem perlindungan paten memang belum ada ketentuan tentang keharusan untuk adanya keterbukaan informasi tentang sumber invensi. Itu sebabnya negara-negara maju yang diuntungkan dengan sistem paten yang berlaku sekarang ini cenderung mempertahankan kondisi yang ada. Sebaliknya, negara berkembang yang merasa diperlakukan tidak adil menginginkan agar aturan hukum paten yang ada mencerminkan rasa keadilan tersebut dengan memasukkan prinsip keterbukaan informasi tentang sumber invensi. Adanya keterbukaan informasi sumber ini akan berdampak bahwa negara-negara berkembang mempunyai landasan yang kuat untuk menuntut adanya pembagian yang adil atas pemanfaatan SDG oleh negara maju.

Sesungguhnya, wacana tentang keterbukaan informasi sumber ini lebih disebabkan karena ada perbedaan kepentingan dalam konteks paten atas obat-obatan dan tanaman pangan. Lebih 
tepatnya menyangkut kepentingan atas access and benefit sharing. Negara maju berkepentingan atas akses yang terbuka terhadap SDG. Sebaliknya, negara berkembang berkepentingan untuk adanya benefit sharing atas pemanfaatan SDG. Boleh dikatakan pergumulan tentang disclosure requirements berkisar pada persoalan access and benefit sharing ini.

Negara-negara maju mencoba bertahan pada aspek hukum berupa kesepakatan internasional yang telah disepakati dalam forum TRIPs. Mereka menuntut agar negara-negara berkembang comply (patuh) terhadap TRIPs dengan memberikan perlindungan paten dengan standard internasional. Sedangkan Negara-negara berkembang menginginkan sistem yang lebih adil yang lebih dekat pada persoalan etika moral. Namun pada kenyataannya etika moral seringkali tidak efektif untuk melahirkan kesadaran manusia agar berlaku adil. Itu sebabnya negara-negara berkembang menuntut agar norma etika moral itu diperkuat dalam bentuk norma hukum. Tuntutan itulah yang mengemuka dalam perdebatan masuknya disclosure requirements dalam proses permohonan paten.

Indonesia adalah salah satu dari negara berkembang yang memiliki sumberdaya genetik dan pengetahuan tradisional yang cukup kaya. Beberapa kejadian telah terungkap bahwa negara maju telah menggunakan SDG Indonesia tanpa aturan yang jelas dan tanpa benefit sharing. Bahkan virus flu burungpun mengalami kejadian demikian. Jadi, sebenarnya tidak ada alasan bagi Indonesia untuk menolak disclosure requirements dimasukkan ke dalam undang-undang paten. Jika perjuangan untuk memasukkan disclosure requirements menghasilkan kesepakatan internasional dalam bentuk legally binding instruments, maka negara maju juga harus patuh terhadap instrumen hukum itu. Artinya, jika disclosure requirements telah diangkat dan diadopsi menjadi kesepakatan internasional, maka semua negara harus mengamandemen undang-undang paten dengan memasukkan disclosure requirements yang dimaksud.

Salah satu cara untuk memasukkan disclosure requirements ke dalam sistem paten adalah dengan menambah persyaratan formal dalam aplikasi paten. Persyaratan itu dinyatakan dalam formulir aplikasi paten berupa tambahan keterangan apakah invensi yang bersangkutan terkait atau menggunakan SDG tertentu dari masyarakat lokal dari negara peserta? Jika invensi tersebut menggunakan SDG yang terkait, maka kelengkapan dokumennya harus disertai dengan dokumen yang menunjukkan adanya Prior Informed Consent (PIC) atau perjanjian antara inventor dengan masyarakat setempat untuk menggunakan SDG yang bersangkutan. Kiranya dokumen semacam ini tidak menambah beban pemeriksa paten dalam rangka pemeriksaan substantif, karena dokumen itu memang tidak membebani persyaratan substantif terhadap invensi yang patentable.

Atau jika disclosure requirements dianggap akan menjadi beban tambahan bagi Kantor Paten, maka beban itu akan dipikul tidak saja oleh Kantor Paten Indonesia, melainkan akan menjadi beban dari seluruh Kantor Paten dari semua negara peserta konvensi. Jika selama ini Indonesia sanggup menjalankan mandat TRIPs dengan pemeriksaan substantif atas 3 (tiga) persyaratan standard patentability of invention, mengapa kemudian harus keberatan terhadap "sedikit" tambahan beban berupa persyaratan formal. 
Kiranya penambahan disclosure requirements ke dalam aplikasi paten justru akan membantu Indonesia dalam melindungi hak-hak masyarakat lokal. Jika disclosure requirements dimasukkan ke dalam undang-undang paten setiap negara peserta TRIPs, maka Indonesia akan sangat terbantu dalam rangka memantau penggunaan SDG Indonesia oleh industri farmasi dunia. Kantor-kantor paten di negara-negara maju akan membantu mengawasi pemanfaatan SDG Indonesia. Itulah manfaat yang mungkin dapat diperoleh dengan adanya disclosure requirements dalam aplikasi paten.

\subsection{Formulasi Pengaturan Hak Paten Terhadap Disclosure Requirements Sumber Daya Genetik}

UU Paten antara lain mengatur tentang hak (Paten), cara memperoleh dan mempertahankan hak, dan pembatasan- pembatasan untuk mewujudkan keseimbangan antara hak dan kewajiban pemilik atau pemegang paten. Walaupun UU Paten merupakan penyempurnaan terhadap undang-undang sebelumnya Undang-Undang Nomor 14 Tahun 2001 yang baru diberlakukan, namun keberadaan UU Paten ini belum mengakomodir berbagai permasalahan tentang perlindungan atas invensi yang timbul dan berkembang di masyarakat, serta mengayomi berbagai kepentingan dari para pemangku kepentingan terkait dengan kebutuhan akan perlindungan atas Paten dan kebebasan menggunakan teknologi yang seharusnya menjadi milik umum. Hal ini diakibatkan oleh kemajuan ilmu pengetahuan dan pengaruh perkembangan teknologi (IPTEK) yang sangat pesat. Perkembangan itu tidak hanya di bidang teknologi tinggi seperti informasi, telekomunikasi, serta bioteknologi, tetapi juga di bidang mekanik, kimia atau lainnya. Di samping itu kesadaran masyarakat juga semakin tinggi untuk meningkatkan pendayagunaan teknologi yang sederhana. Sesuai dengan tujuan pemberian Paten yaitu untuk memberikan penghargaan atas suatu hasil karya berupa invensi baru yang dengan adanya penghargaan dimaksud akan mendorong invensi teknologi baru, maka sudah sepatutnya undang-undang memberikan perlindungan atas Invensi dimaksud bagi para Inventornya.

Beberapa negara telah merumuskan (formulasi) ketentuan disclosure requirements di dalam undang-undang patennya, langkah-langkah yang disebut dengan transparansi, yang bertujuan untuk memastikan mengenai hukum asal dari SDG yang dipatenkan tersebut. Negara-negara tersebut adalah: ${ }^{12}$

1. Belgia; Patent Law; Project: Law No. 2005-04-28/33: Loi modifiant la loi du 28 mars 1984 sur les brevets d'invention, en ce qui concerne la brevetabilité des inventions biotechnologiques.),

2. Bolivia; Supreme Decree No. 24676, Article 2, Final Provisions VII - Seventh,

3. Brazil; Provisional Measure No. 2.186-16 (23 August 2001),

12 Thomas Henninger, 2009, Disclosure Requirements in Patent Law and Related Measures: A Comparative Overview of Existing National and Regional Legislation on IP and Biodiversity, "Diálogo Centroamericano sobre medidas relacionadas con la biodiversidad y el sistema de PI", Costa Rica: ICTSD, BMZ, and GTZ in cooperation with Cenpromype, SIECA and INBio, h. 4 
4. China; Patent Law Amendment (2008), Article 5(2), 26(5),

5. Kosta Rika; Biodiversity Law 7788, Article 80; Rules on Access (2003) Art. 25,

6. Denmark; Act 412, 31 May 2000 amending Danish Patent Act, paragraph 3; Danish Penal Code 163,

7. Mesir; Egyptian Law No. 82 of 2002 on the Protection of Intellectual Property Rights, Art. 13,

8. Selandia Baru; Patent Bill 2009 and Section 17 Patent Act (1953),

9. Norwegia; Patent Law Amendment 2004, Section 8b,

10. Panama; Executive Decree No. 25 (28 April 2009) Art. 19,

11. Portugal; Biodiversity Law (10 August 2002) Ar. 4c ,

12. Romania; Patent Law 64/1991, rule 14.1.c) source shall be indicated,

13. Afrika Selatan; Patent Law Amendment (7 December 2005),

14. Swiss; Amendment of Patent Law of 22 June 2007, RO 2008 2551, Art. 49 a,

15. Thailand; Act on Protection and Promotion of Traditional Thai Medicinal Intelligence B.E. 2542 ,

16. Venezuela; Biodiversity Law 2009.

Dari beberapa Negara yang telah merumuskan disclosure requirements dalam pengaturan Paten, maka dibandingkan UU Paten di Indonesia, salah satu kelemahan dalam substansi UUPaten yaitu belum mengatur secara jelas invensi yang berkaitan dengan dan/atau berasal dari sumber daya genetik. Ketentuan mengenai kewajiban pengungkapan/informasi (disclosure requirements) dalam permohonan Paten tentang sumber teknologi apabila teknologi tersebut berasal dari sumber daya genetik dari masyarakat lokal. Paten yang berasal dari sumber daya genetik harus memberi manfaat bagi masyarakat di lingkungan di mana sumber daya genetik tersebut berasal, artinya menyisihkan sebagian manfaat invensi bagi pemilik sumber daya genetik (benefit sharing).

Bentuk dari disclosure requirements ini ada 3 yaitu pengaturan yang bersifat wajib (mandatory), pengaturan yang bersifat sukarela (voluntary), dan disclosure requirements dengan disertai bukti hukum (proof of legal acquisition). Bentuk disclosure requirements wajib berhubungan dengan patentabilitas, pencabutan paten, dan pembatalan, di dalam disclosure requirements menyediakan sanksi berupa sanksi pidana dan sanksi administrasi terhadap pelanggaran atau tidak terpenuhinya disclosure requirements di dalam permohonan paten. Bentuk disclosure requirements sukarela sebagai bagian dari formalitas, kelalaian dalam mengungkapkan asal SDG didalam permohonan paten tidak akan menjadikan permohonanan paten tersebut didiskualifikasi. Dengan kata lain disclosure requirements bentuk ini tidak memberikan kekuatan hukum mengikat dan tanpa sanksi, menjadikan bentuk ini menjadi bentuk pengungkapan yang paling lemah. 
Bentuk disclosure requirements yang terakhir adalah disclosure requirements yang menyertakan bukti hukum dari negara asal SDG (sertifikat SDG, PIC atau ABS). Bentuk disclosure requirements ini merupakan bentuk yang agak berbeda dari 2 bentuk lainnya, dimana disclosure requirements ini merupakan pengungkapan asal persyaratan yang mengikat sistem hak paten lebih dekat kepada akses pengaturan CBD dan ketentuan ABS, khususnya untuk ABS yang beroperasi di negara-negara yang langsung menyediakan SDG dan/atau pengetahuan tradisional.

Beberapa negara mengaplikasikan disclosure requirements hanya untuk hukum paten saja, seperti Denmark, Mesir, EC, Portugal, India, Swedia dan Swiss. Tetapi di beberapa negara lain, memperluas pengaplikasian disclosure requirements dengan HKI yang lainnya salah satunya adala Selandia Baru, dimana merek dagang juga dapat dilindungi dengan pengaturan disclosure requirements. sedangkan di negara lainnya menyediakan pengaturan disclosure requirements untuk perlindungan varietas tanaman seperti Kosta Rika, Malaysia, dan Thailand. Di kelompok negara lainnya memberikan pengaturan disclosure requirements untuk semua bidang HKI seperti Andean Community, the African Community, Brazil, Panama, Filipina, Peru, Venezuela, dan Vietnam. Hal ini terjadi karena negara-negara tersebut telah memperkenalkan disclosure requirements ke dalam legislasi Kenekaragaman Hayati untuk menghindari terjadinya penyalahgunaan SDG.

Kesemua negara tersebut terlihat sangat serius untuk menangani permasalahan mengenai pemanfaatan SDG yaitu dengan memasukan disclosure requirements ke dalam UU sebagai syarat aplikasi permohonan paten. Dimasukkannya disclosure requirements ke dalam UU dapat dikatakan merupakan suatu ketegasan. Pemohon paten tidak dapat dengan mudah memasukkan permohonan apabila terkait dengan SDG, dengan berbagai syarat yang ada dan juga sanksi yang diberikan. Meskipun sanksi yang diberikan tidak semuanya berupa sanksi pidana, tetapi dengan memasukkan sanksi saja sudah memberikan gambaran keseriusan negara untuk melindungi SDG nya.

Sedangkan Indonesia di dalam UU Paten, belum merumuskan ketentuan mengenai disclosure requirements sebagai salah satu syarat permohonan paten. Ketentuan mengenai kewajiban pengungkapan dalam permohonan Paten tentang sumber teknologi apabila teknologi tersebut berasal dari sumber daya genetik dari masyarakat lokal. Paten yang berasal dari sumber daya genetik harus memberi manfaat bagi masyarakat di lingkungan dimana sumber daya genetik tersebut berasal, artinya menyisihkan sebagian manfaat invensi bagi pemilik sumber daya genetik (benefit sharing). Persyaratan permohonan paten saat ini hanya sesuai dengan mandat TRIPs yaitu dengan pemeriksaan substantif atas 3 (tiga) persyaratan standard patentability of invention.

\section{PENUTUP}

a. Pemanfaatan SDG mempunyai implikasi pada ketahanan pangan lokal dan nasional. Dari sudut pandang liberalisme paten, invensi apapun, termasuk yang terhubung dengan 
SDG selalu dapat dimintakan paten, asalkan memenuhi persyaratan standar berupa: novelty (kebaruan), non-obvious (bersifat inventif), and useful (kebergunaan).

b. Ketentuan mengenai kewajiban pengungkapan/informasi (disclosure requirements) dalam permohonan Paten tentang sumber teknologi apabila teknologi tersebut berasal dari sumber daya genetik dari masyarakat lokal. Paten yang berasal dari sumber daya genetik harus memberi manfaat bagi masyarakat di lingkungan di mana sumber daya genetik tersebut berasal, artinya menyisihkan sebagian manfaat invensi bagi pemilik sumber daya genetik (benefit sharing).

c. Kiranya penambahan disclosure requirements ke dalam aplikasi paten justru akan membantu Indonesia dalam melindungi hak-hak masyarakat lokal. Jika disclosure requirements dimasukkan ke dalam undang-undang paten setiap negara peserta TRIPs, maka Indonesia akan sangat terbantu dalam rangka memantau penggunaan SDG Indonesia oleh industri farmasi dunia. Kantor-kantor paten di negara-negara maju akan membantu mengawasi pemanfaatan SDG Indonesia. Itulah manfaat yang mungkin dapat diperoleh dengan adanya disclosure requirements dalam aplikasi paten.

\section{DAFTAR PUSTAKA}

\section{A. Buku}

Setyowati, Krisnani. 2005. Hak Kekayaan Intelektual dan Tantangan Implementasinya di Perguruan Tinggi. Bogor: Kantor HKI-IPB.

Poerwanto, Roedhy Iskandar Zulkarnaen Siregar, Ani Suryani. Tanpa Tahun. Merevolusi Revolusi Hijau: Pemikiran Guru Besar IPB (Buku III). IPB Press.

Henninger, Thomas. 2009. Disclosure Requirements in Patent Law and Related Measures: A Comparative Overview of Existing National and Regional Legislation on IP and Biodiversity, "Diálogo Centroamericano sobre medidas relacionadas con la biodiversidad y el sistema de PI". Costa Rica: ICTSD, BMZ, and GTZ in cooperation with Cenpromype, SIECA and INBio.

\section{B. Disertasi}

Agus Sardjono. 2004. "Negara Maju Vs Negara Berkembang : Studi Mengenai Kemungkinan Perlindungan Pengetahuan Obat Obatan Tradisional Sebagai Kekayaan Intelektual di Indonesia”. Disertasi. Fakultas Hukum Universitas Indonesia. Jakarta.

C. Internet

Country Profile Indonesia dalam Balai Kliring Keanekaragaman Hayati, http://bk.menlh.go.id/?modul $\mathrm{e}=$ pages\&id $=$ cprofile. 
http://www.antaranews.com/print/369592/masuknya-jenis-ikan-asing-harus-selektif

\section{Peraturan Perundang-Undangan}

Undang-Undang Dasar Negara Republik Indonesia Tahun 1945.

Undang-Undang Nomor 14 Tahun 2001 tentang Paten, Lembaran Negara Republik Indonesia Tahun 2001 Nomor 109 Indonesia.

United Nations, the Convention on Biological Diversity 1992.

United Nations, the Agreement of Trade Related Intellectual Property Right 1994. 